\title{
Biosynthesis of Rat Serum Albumin
}

\author{
By J. D. JUDAH AND MARION R. NICHOLLS \\ Department of Experimental Pathology and Medical Research Council Research Group in \\ Experimental Pathology, University College Hospital Medical School, London WC1E 6JJ, U.K.
}

\section{(Received 8 March 1971)}

\begin{abstract}
1. The labelling of intracellular and extracellular serum albumin was studied in liver slices and in whole rats by using new methods for the purification of the protein. 2. The results suggest that a polypeptide precursor is formed that is converted relatively slowly into serum albumin. 3. The effect of liver cell $\mathrm{K}^{+}$has been examined by a double-label method and it is shown that $\mathrm{K}^{+}$accelerates the rate of conversion of 'precursor' into albumin. The rate of transit of albumin across the cell membrane appears to be unrelated to the concentration of $\mathrm{K}^{+}$within the cell. 4. The time-course of incorporation of radioactive amino acid into albumin follows a sigmoidal mode. There is a pronounced time-lag before label starts to appear in intracellular albumin, and a further time-lag before it appears in extracellular albumin. 5. In slices the sum of intra- and extra-cellular label rises steadily from $30 \mathrm{~min}$ after the start of labelling with a pulse of labelled leucine or valine and continues to rise for at least another $60 \mathrm{~min}$. This occurs whether labelling is stopped by addition of excess of carrier amino acid or with cycloheximide $(100 \mu \mathrm{M})$ or both. 6. The intracellular albumin content remains constant whether slices are maintained with low or normal intracellular $\mathrm{K}^{+}$concentrations. 7. Specific radioactivities of intracellular albumin (and fractions thereof) and of extracellular albumin were determined in vitro and in vivo. The results show that the intracellular albumin cannot be a precursor of extracellular albumin, unless a very small compartment is turning over much more rapidly than the bulk of the liver albumin or even of the microsomal albumin.
\end{abstract}

In a previous paper (Judah \& Nicholls, 1970) we showed that the secretion of serum albumin was linearly related to liver cell $\mathrm{K}^{+}$, and that secretion was independent of protein synthesis. In the present work, we have studied the incorporation of labelled leucine and valine into intracellular and extracellular serum albumin to determine the site of action of $\mathrm{K}^{+}$on the movement of serum albumin from its point of synthesis to the outer boundary of the liver cell.

The problems of isolation of radiochemically pure serum albumin have been described by Schreiber, Rotermund, Maeno, Weigand \& Lesch (1969). In the accompanying paper (Judah \& Nicholls, 1971) we describe simple methods for the isolation of serum albumin of sufficient purity for our work.

\section{MATERIALS AND METHODS}

Animals. Female Wistar rats obtained from A. Tuck and Sons, Rayleigh, Essex, U.K., were kept in our animal house until they weighed about $200 \mathrm{~g}$. Diet and other details were as described by Judah \& Nicholls (1970).

Composition of Ringer solution. This contained $\mathrm{NaCl}$ (140 mM); $\mathrm{KCl}$ (7.7 mM unless otherwise specified); $\mathrm{MgSO}_{4}$
(1.3 mM); $\mathrm{CaCl}_{2}(1.86 \mathrm{mM}) ; \mathrm{Na}_{2} \mathrm{HPO}_{4}$ (1.3 mM adjusted to pH 7.40 with $\mathrm{HCl}$ ) and tris-HCl buffer (30 mM); pH 7.40, adjusted for temperature of incubation. The Ringer solution also contained $0.1 \mathrm{~mm}$ (final concentration) of the 20 common amino acids including L-leucine. The incubation temperature was $30^{\circ} \mathrm{C}$ and the gas phase was oxygen.

Maintenance of slice $\mathrm{K}^{+}$content. This was done as described by Judah \& Nicholls (1970), as were all methods except for those described below.

Purification of labelled albumin. This was done after antibody precipitation and release of albumin from the precipitate (Gordon \& Humphrey, 1961). The soluble proteins were purified by ion-exchange chromatography as described in the accompanying paper (Judah \& Nicholls, 1971).

Intracellular albumin was released by homogenization of livers or liver slices or of cell fractions and treatment of the suspension with approx. $0.6 \%(\mathrm{w} / \mathrm{v})$ final concentration of sodium deoxycholate, pH 7.4. This treatment was followed by centrifugation $\left(100000 \mathrm{~g}_{\text {av. }}\right.$ for $\left.60 \mathrm{~min}\right)$. The clear supernatant was subjected to antibody precipitation. This precipitate was then purified as above. Full details may be found in the accompanying paper.

Content of serum albumin in tissues and Ringer solution. This was measured by isotope dilution, antibody precipitation and purification as described in the accompanying paper (Judah \& Nicholls, 1971). 
Incorporation of labelled amino acid into slice proteins. Slices were cut and allowed to reach a steady state by incubation for $60 \mathrm{~min}$ in Ringer solution of the desired composition. They were then labelled for 10-20 min (as specified in the text and Tables) with ${ }^{14} \mathrm{C}$ - or ${ }^{3} \mathrm{H}$-labelled amino acid. Labelling was stopped either by addition of cycloheximide $(100 \mu \mathrm{M})$ or unlabelled amino acid $(5 \mathrm{mM})$. At 5 min after the addition the slices were transferred to fresh Ringer solution containing cycloheximide (100 $\mu \mathrm{M})$ or unlabelled amino acid or both. Samples were withdrawn at intervals thereafter as specified in the text and Tables. Slices were homogenized (about $10 \%, w / v$ ) in $150 \mathrm{~mm}-\mathrm{NaCl}$ containing $20 \mathrm{~mm}$-tris- $\mathrm{HCl}, \mathrm{pH} \mathrm{7.40}$, at $0^{\circ} \mathrm{C}$. The homogenate was treated with sodium deoxycholate (0.5\% final concentration), and after $15 \mathrm{~min}$ was centrifuged for $60 \mathrm{~min}$ at $105000 \mathrm{~g}$. The supernatant was used for separation of intracellular albumin. The bathing Ringer solution was centrifuged at $10000 \mathrm{~g}$ for $10 \mathrm{~min}$ to remove debris and the clear supernatant was used for separation of extracellular albumin.

Effect of $\mathrm{K}^{+}$on emergence of albumin from the cell. At $30^{\circ} \mathrm{C}$, some $30-40 \mathrm{~min}$ passes between addition of labelled amino acid and emergence of labelled albumin from the cells. This 'lag period' or 'transit time' has frequently been observed (e.g. Judah \& Nicholls, 1970). Because of the sigmoidal mode of appearance of label in extracellular albumin it is difficult to tell by inspection the time at which this appearance occurs, or whether the concentration of cellular $\mathrm{K}^{+}$affects it. If two sets of slices are each consecutively labelled with ${ }^{3} \mathrm{H}$ - and ${ }^{14} \mathrm{C}$-labelled amino acid, and the ${ }^{3} \mathrm{H} /{ }^{14} \mathrm{C}$ ratio is measured in the purified albumin, then if the lag period is different in the two systems, the ${ }^{3} \mathrm{H} /{ }^{14} \mathrm{C}$ ratio will also be different at any given time. The difference will be most marked at times near the time of emergence and will tend to diminish later. Two sets of slices were incubated in Ringer solution under $\mathrm{O}_{2}$ at $30^{\circ} \mathrm{C}$ for $60 \mathrm{~min}$. One set contained approx. $180 \mu \mathrm{mol}$ of $\mathrm{K}^{+} / \mathrm{g}$ dry wt. and the second about $300 \mu \mathrm{mol} / \mathrm{g}$ dry wt. They were then labelled for $15 \mathrm{~min}$ with $\mathrm{L}$ $\left[4,5 \cdot{ }^{3} \mathrm{H}_{2}\right]$ leucine (specific radioactivity $35 \mu \mathrm{Ci} / \mu \mathrm{mol}$ ). The slices were transferred to fresh Ringer solution containing $5 \mathrm{~mm}$-L-leucine. Then $15 \mathrm{~min}$ after this transfer, $\mathrm{L}-\left[\mathrm{U}-{ }^{14} \mathrm{C}\right] \mathrm{valine}$ (specific radioactivity $6 \mu \mathrm{Ci} / \mu \mathrm{mol}$ ) was added. After a further $15 \mathrm{~min}$, labelling was stopped by addition of $5 \mathrm{~mm}$-L-valine and $100 \mu \mathrm{M}$-cycloheximide. The ${ }^{3} \mathrm{H} /{ }^{14} \mathrm{C}$ ratio was determined in purified intracellular and extracellular albumin at intervals of $30-60 \mathrm{~min}$ after addition of $\left[{ }^{14} \mathrm{C}\right]$ valine.

Experiments with whole rats. Female rats (about $200 \mathrm{~g}$ body wt.) were given $5.0 \mu \mathrm{Ci}$ of $\mathrm{L}-\left[1{ }^{14} \mathrm{C}\right]$ leucine (specific radioactivity $10 \mu \mathrm{Ci} / \mu \mathrm{mol}$ ) by intraperitoneal injection. At specified intervals they were bled under light ether anaesthesia into heparinized tubes. The livers were removed to ice-cold $150 \mathrm{mM}-\mathrm{NaCl}$, containing $1.8 \mathrm{~mm}$ $\mathrm{CaCl}_{2}$ and $20 \mathrm{~mm}$-tris- $\mathrm{HCl}, \mathrm{pH} 7.40$, and sliced coarsely. They were rinsed with three further changes of the same medium to remove blood, and then homogenized in $150 \mathrm{~mm}-\mathrm{NaCl}-30 \mathrm{~mm}$-tris-HCl, pH 7.40, to make a $10 \%$ (w/v) homogenate. The homogenate was divided into two portions. One was treated with 0.33 vol. of $2.6 \%(w / v)$ sodium deoxycholate, left for $15 \mathrm{~min}$ and centrifuged at $105000 \mathrm{~g}_{\mathrm{av}}$. for $60 \mathrm{~min}$ to obtain 'total' serum albumin. The other portion was centrifuged at $7000 \mathrm{~g}$ for $10 \mathrm{~min}$ and the supernatant centrifuged at $105000 \mathrm{~g}_{\mathrm{av}}$. for $60 \mathrm{~min}$. The
$105000 \mathrm{~g}$ supernatant was collected to give 'soluble' albumin. The microsomal preparation was resuspended in $105 \mathrm{~mm}-\mathrm{NaCl}-20 \mathrm{~mm}$-tris- $\mathrm{HCl}, \mathrm{pH} \mathrm{7.40}$, and treated with sodium deoxycholate (final concentration $0.5 \%$ ). After $15 \mathrm{~min}$ the mixture was centrifuged at $105000 \mathrm{~g}_{\mathrm{av}}$. for $60 \mathrm{~min}$. The supernatant was collected to give 'microsomal' albumin. The three extracts were treated with anti-albumin serum and the precipitates collected and processed as described above.

Radioactivity was determined by scintillation spectrometry as described by Judah \& Nicholls (1970). When mixtures of ${ }^{3} \mathrm{H}$ and ${ }^{14} \mathrm{C}$ were to be assessed, the spectrometer was set to allow only $10 \%$ cross-over from the ${ }^{14} \mathrm{C}$ to the ${ }^{3} \mathrm{H}$ channel. The results were corrected for this. Since in these double-label experiments we were interested only in the ratios between the two isotopes, no correction was made for quenching. Automatic external standardization was used to monitor the extent of quench, so that this should not influence the results.

\section{RESULTS}

Time-course of labelling of serum albumin. Fig. 1 shows the relationships between the appearance of $\left[{ }^{14} \mathrm{C}\right]$ leucine in intra- and extra-cellular albumin. After a 10-15 min period of exposure to L- $\left[1-{ }^{14} \mathrm{C}\right] \mathrm{leu}$ cine, the total radioactivity in serum albumin rises for at least $60 \mathrm{~min}$. The radioactivity of extracellular serum albumin increases more slowly than that of intracellular albumin. These experiments were repeated five times with similar results. Because of the variation from experiment to experiment that we have noted before (Judah \& Nicholls, 1970), the means and standard deviations are not recorded.

The labelling of total liver protein (not shown) remained constant throughout the period of observation, at about 1000d.p.m./mg of slice protein. In these experiments, the labelling was stopped with $5.0 \mathrm{~mm}$-carrier leucine, but identical results were obtained if $100 \mu \mathrm{M}$-cycloheximide was used instead.

If the experiment was done with $\left[{ }^{3} \mathrm{H}\right]$ leucine followed by $\left[{ }^{14} \mathrm{C}\right]$ leucine, the two radioisotopes followed an identical time-course of incorporation (Fig. 2). Proof that cycloheximide was stopping incorporation was obtained by adding it between the ${ }^{3} \mathrm{H}$-labelled amino acid and the ${ }^{14} \mathrm{C}$-labelled amino acid. No ${ }^{14} \mathrm{C}$ appeared in extracellular albumin after $100 \mathrm{~min}$, and only $5 \%$ of the expected amount in intracellular albumin.

These results are compatible with the synthesis of a peptide that is converted into serum albumin by a process independent of protein synthesis.

The results in Fig. 2 also show that the entry of ${ }^{14} \mathrm{C}$ into the tritiated pools occurs most rapidly in the total slice protein, next in intracellular albumin and last in extracellular albumin.

Action of $\mathrm{K}^{+}$on the synthesis of serum albumin. We labelled slices with $\mathrm{L}-\left[1{ }^{14} \mathrm{C}\right] \mathrm{leucine}$ for $15 \mathrm{~min}$, keeping cellular $\mathrm{K}^{+}$constant at about $180 \mu \mathrm{mol} / \mathrm{g}$ 


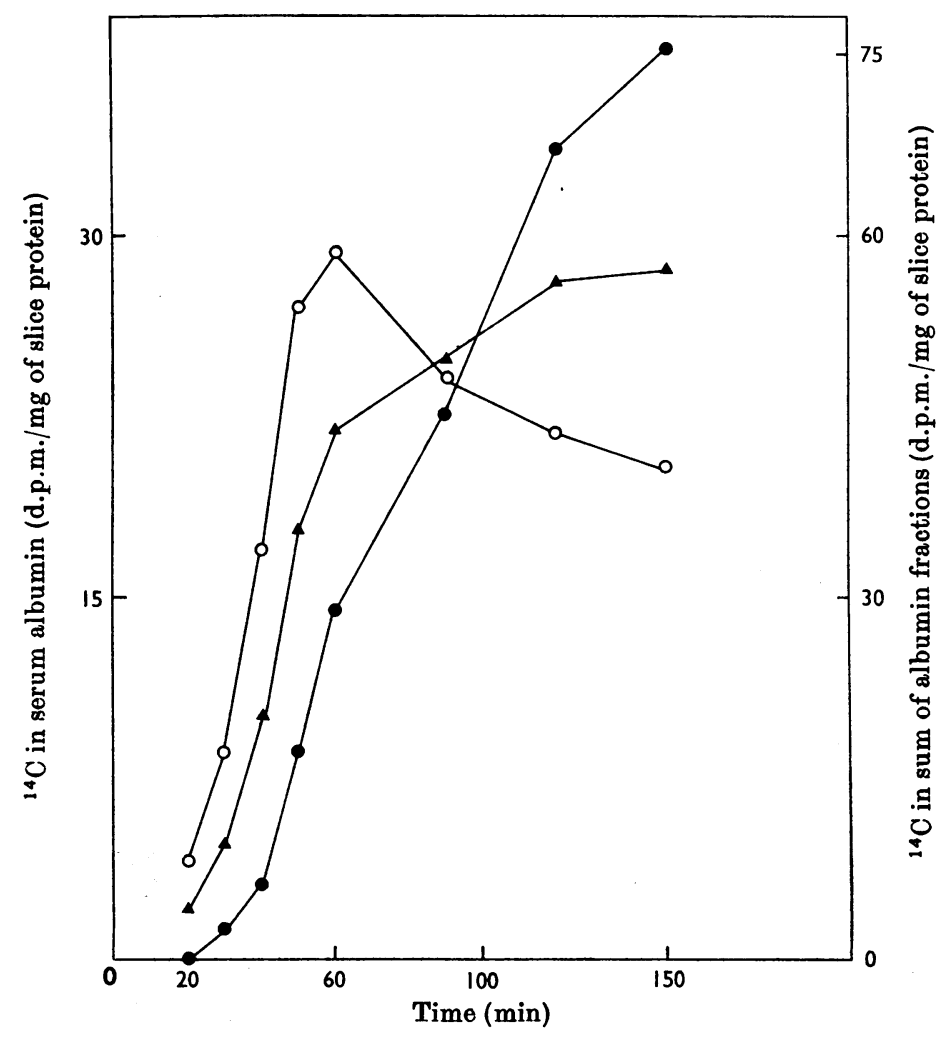

Fig. 1. Time-course of labelling of intracellular and extracellular serum albumin. Two sets of 10 slices were incubated in $50 \mathrm{ml}$ of Ringer solution, containing $7.7 \mathrm{mM}-\mathrm{K}^{+}$and $30 \mathrm{~mm}$-tris-HCl, pH 7.40 at $30^{\circ} \mathrm{C}$, with $\mathrm{O}_{2}$ as gas phase. After $60 \mathrm{~min}, 20 \mu \mathrm{Ci}$ of $\mathrm{L}-\left[1-{ }^{14} \mathrm{C}\right]$ leucine (specific radioactivity $3 \mu \mathrm{Ci} / \mu \mathrm{mol}$ ) was added. After $10 \mathrm{~min}$, $5.0 \mathrm{~mm}$-L-leucine was added, and $5 \mathrm{~min}$ later the slices were transferred in batches of four slices to each of five $150 \mathrm{ml}$ beakers containing $20 \mathrm{ml}$ of Ringer solution, which also contained $5 \mathrm{mM}$-L-leucine (zero time). At the times shown, a batch of four slices was removed and the albumin in slices and Ringer solution separated as described in the Materials and Methods section. O, Intracellular albumin; $\bullet$, extracellular albumin; $\Delta$, sum of intracellular and extracellular albumin.

dry wt. After the labelling was stopped, half the slices were allowed to take up $\mathrm{K}^{+}$to about 300 $\mu \mathrm{mol} / \mathrm{g}$ dry wt., and the time-course of the appearance of label in intracellular and extracellular albumin was followed. No difference was observed in the rate of labelling of intracellular albumin. The extracellular albumin was, as expected, much more rapidly labelled in the presence of $\mathrm{K}^{+}$. We observed, however, that the sum of intracellular and extracellular albumin was higher in the slices containing more $\mathrm{K}^{+}$and we therefore examined this phenomenon as follows.

For each experiment, three sets of five slices were set up in three vessels. Two sets were incubated in a $\mathrm{K}^{+}$-free Ringer solution so as to attain a steadystate $\mathrm{K}^{+}$content of about $170-180 \mu \mathrm{mol}$ of $\mathrm{K}^{+} / \mathrm{g}$ dry wt. (Judah \& Nicholls, 1970). The third set, incubated in Ringer solution containing $7.7 \mathrm{~mm} \cdot \mathrm{K}^{+}$, attained a normal $\mathrm{K}^{+}$content of about $300 \mu \mathrm{mol} / \mathrm{g}$ dry wt. All three sets were then labelled for $20 \mathrm{~min}$ at $30^{\circ} \mathrm{C}$, after which labelling was stopped with $100 \mu \mathrm{M}$-cycloheximide, and $10 \mathrm{~min}$ later the slices were transferred to fresh vessels containing Ringer solution and $100 \mu \mathrm{M}$-cycloheximide. Of the two sets incubated in $\mathrm{K}^{+}$-free Ringer solution, one was transferred to $\mathrm{K}^{+}$-free medium and the other to Ringer solution contrining $7.7 \mathrm{~mm}-\mathrm{K}^{+}$. The third set also was transferred to fresh Ringer solution containing $7.7 \mathrm{~mm}-\mathrm{K}^{+}$. Incubation was allowed to continue for a further $110 \mathrm{~min}$. At this time other experiments indicated that the sum of radioactivity in intracellular and extracellular albumin had reached a constant value. The slices and Ringer solution were separated and the radioactivity of the albumin in each was determined. Table 1 illustrates a typical experiment, which shows a marked 


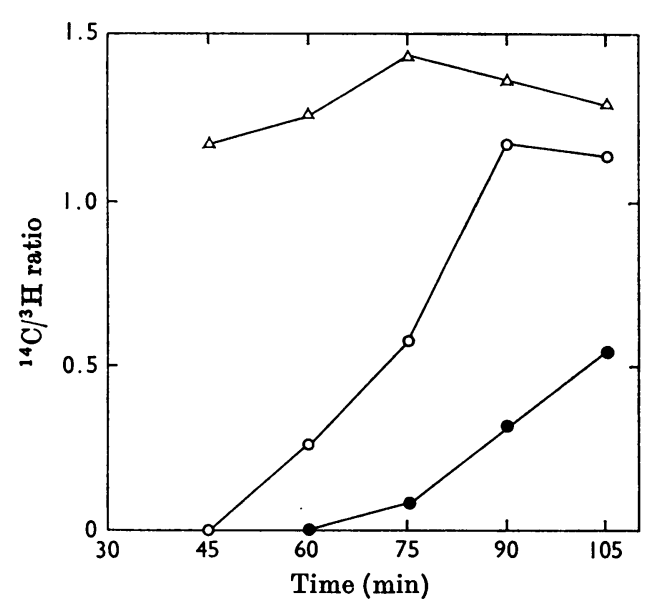

Fig. 2. Time-course of labelling with $\mathrm{L}-\left[4,5-{ }^{3} \mathrm{H}\right]$ leucine followed by $\mathrm{L}-\left[1-{ }^{14} \mathrm{C}\right]$ leucine. The details are as described in Fig. 1, except that the first period of labelling was done with $L-\left[4,5-{ }^{3} \mathrm{H}\right]$ leucine (specific radioactivity $35 \mu \mathrm{Ci}$ / $\mu \mathrm{mol})$. The slices were then transferred to fresh Ringer solution containing $5 \mathrm{~mm}$-leucine, and $15 \mathrm{~min}$ later taken to a third batch of Ringer solution, without carrier and containing $\mathrm{L}-\left[1-{ }^{14} \mathrm{C}\right]$ leucine (specific radioactivity 6 $\mu \mathrm{Ci} / \mu \mathrm{mol})$. The slices were allowed to take up label for 15 min and were then transferred yet again, four slices in a batch to beakers containing $20 \mathrm{ml}$ of Ringer solution containing $5 \mathrm{~mm}$-leucine. At this time (45 min in Fig. 2), the first set of four slices were homogenized as described in the Materials and Methods section. $\Delta$, Total slice protein; $O$, intracellular albumin; $\bullet$, extracellular albumin.

increase in radioactivity in the total albumin when $\mathrm{K}^{+}$is added after labelling is stopped. The results also suggest that incubation at high $\mathrm{K}^{+}$throughout the experiment stimulates incorporation of $\left[{ }^{14} \mathrm{C}\right] \mathrm{leu}$ cine even more.

The effect of increasing cell $\mathrm{K}^{+}$after labelling varies but in each of six experiments there was always a stimulation. Table 2 gives the extent of these stimulations (means \pm S.D.) for six consecutive experiments.

These results, compatible with a direct effect of $\mathrm{K}^{+}$on the conversion of 'precursors' into complete albumin, further suggest that the synthesis of 'precursor' itself also is affected by $\mathrm{K}^{+}$, since the system labelled and incubated at a normal $\mathrm{K}^{+}$content always does better than the one that is adjusted to normal $\mathrm{K}^{+}$content at the end of labelling.

Effect of $\mathrm{K}^{+}$on transit of serum albumin. We examined the possibility that $\mathrm{K}^{+}$might affect the time of transit of serum albumin across the cell, using the double-label technique described in the Materials and Methods section, comparing slices with $\mathrm{K}^{+}$content about $180 \mu \mathrm{mol} / \mathrm{g}$ dry wt. with those containing about $300 \mu \mathrm{mol} / \mathrm{g}$ dry wt.
The ${ }^{14} \mathrm{C} /{ }^{3} \mathrm{H}$ ratio in six experiments was unaltered when low $\mathrm{K}^{+}$was compared with high $\mathrm{K}^{+}$, the ratio at low $\mathrm{K}^{+}$being $0.97 \pm 0.19$ of that at high $\mathrm{K}^{+}$ for extracellular albumin and $0.99 \pm 0.15$ for intracellular albumin.

Energy dependence. Slices were labelled for $20 \mathrm{~min}$, $100 \mu \mathrm{M}$-cycloheximide was added and $5 \mathrm{~min}$ later the slices were transferred to fresh vessels containing 2,4-dinitrophenol $(100 \mu \mathrm{M})$ and cycloheximide $(100 \mu \mathrm{M})$ or without dinitrophenol. No effect was observed on the appearance of label in intra- or extra-cellular albumin.

Origin of the extracellular albumin. The above results raised the possibility that intracellular albumin might not be the precursor of extracellular albumin. We therefore measured intracellular albumin and determined its specific radioactivity, which we compared with that of extracellular serum albumin.

The content of serum albumin in liver slices remains constant for at least $180 \mathrm{~min}$, at about $1.5 \mathrm{mg} / \mathrm{g}$ dry wt. This value accords well with observations on whole rat liver (Gordon \& Humphrey, 1961). Slice albumin is not influenced by a concentration of intracellular $\mathrm{K}^{+}$as low as 150 $\mu \mathrm{mol} / \mathrm{g}$ dry wt. In Table 3, we show an experiment corresponding to that shown in Table 1, showing that when $\mathrm{K}^{+}$is added to the system after labelling is arrested with cycloheximide $(100 \mu \mathrm{M})$, the specific radioactivity of the serum albumin is raised markedly over that of the untreated control. Further, the specific radioactivity of the extracellular albumin rises far above that of the intracellular. Since the presence of cycloheximide prohibits the entry of unlabelled as well as of labelled amino acid into the protein, this experiment (which was repeated five times) must mean that most of the intracellular albumin cannot be the precursor of the extracellular albumin.

However, the double-label experiments (Fig. 2) suggest very strongly that some fraction of intracellular albumin is the precursor of extracellular albumin, since the ${ }^{14} \mathrm{C} /{ }^{3} \mathrm{H}$ ratios measure the entry of ${ }^{14} \mathrm{C}$-labelled protein into the newly formed (tritiated) pool. Four possibilities present themselves: (1) that only a fraction of the cells is making labelled serum albumin at the time of the experiment; (2) that only a fraction of the intracellular albumin is the precursor for the extracellular albumin; (3) that a common precursor is the source of the intracellular and extracellular albumins, which are independent of each other; (4) that a combination of these is at work.

We therefore repeated the experiment of Peters (1962) with whole rats to see if an answer was possible. Fig. 3(a) shows the results. They are similar to those reported by Peters (1962) with the notable difference that only a small fraction of the 
Table 1. Incorporation of $\mathrm{L}-\left[1-{ }^{14} \mathrm{C}\right]$ leucine into total slice protein and albumin of rat liver slices

The experiment was done in three sequential operations. Three sets of six slices each were incubated for $60 \mathrm{~min}$ in Ringer solution (one set) or $\mathrm{K}^{+}$-free Ringer solution (two sets) (Incubation 1 ). They were then labelled for $20 \mathrm{~min}$ with $\mathrm{L}-\left[1-{ }^{14} \mathrm{C}\right]$ leucine (specific radioactivity $4 \mu \mathrm{Ci} / \mu \mathrm{mol}$ ) in the same media (Labelling), at the end of which $100 \mu \mathrm{M}$-cycloheximide was added. At $5 \mathrm{~min}$ later, the slices were transferred to fresh vessels, sets 1 and 3 to a medium as before and set 2 from a $\mathrm{K}^{+}$-free to a normal Ringer solution. The fresh media contained 100 $\mu \mathrm{M}$-cycloheximide together with $5 \mathrm{mM}$-L-leucine in a volume of $30 \mathrm{ml}$. This incubation (Incubation 2 ) continued for $105 \mathrm{~min}$ from the time of transfer of slices at a temperature of $30^{\circ} \mathrm{C}$ and a gas phase of $\mathrm{O}_{2}$.

\begin{tabular}{|c|c|c|c|c|c|c|c|}
\hline \multirow[b]{3}{*}{ Set no. } & \multirow{2}{*}{\multicolumn{3}{|c|}{ Concn. of $\mathrm{K}^{+}$in Ringer solution (mM) during }} & \multicolumn{4}{|c|}{${ }^{14} \mathrm{C}$ (d.p.m./mg of slice protein) } \\
\hline & & & & \multirow{2}{*}{$\begin{array}{c}\text { Slice } \\
\text { protein }\end{array}$} & \multirow{2}{*}{$\begin{array}{l}\text { Intracellular } \\
\text { albumin (I) }\end{array}$} & \multirow{2}{*}{$\begin{array}{l}\text { Extracellular } \\
\text { albumin (E) }\end{array}$} & \multirow[b]{2}{*}{$\mathbf{E}+\mathbf{I}$} \\
\hline & Incubation $\mathbf{l}$ & Labelling & Incubation 2 & & & & \\
\hline 1 & 0.0 & 0.0 & 0.0 & 1300 & 15 & 13 & 28 \\
\hline 2 & 0.0 & 0.0 & 7.7 & 1010 & 15 & 22 & 37 \\
\hline 3 & 7.7 & 7.7 & 7.7 & 1340 & 20 & 21 & 41 \\
\hline
\end{tabular}

Table 2. Effect of $K^{+}$on labelling of intracellular and extracellular serum albumin

The experiments were all done as described in Table 1, the period of labelling being ended by addition of $100 \mu \mathrm{M}$-cycloheximide and of $5 \mathrm{mM}$-leucine as there described. The results are the means \pm S.D. of the ratios of radioactivities (normal $\mathrm{K}^{+} /$low $\mathrm{K}^{+}$) of the protein fractions indicated in six consecutive experiments in each group.

\begin{tabular}{|c|c|}
\hline \multicolumn{2}{|c|}{$\begin{array}{c}\mathrm{K}^{+} \text {in Ringer solution (mM) } \\
\text { during }\end{array}$} \\
\hline Labelling & Incubation 2 \\
\hline 0.0 & 7.7 \\
\hline & \\
\hline
\end{tabular}

\begin{tabular}{ccc}
\multicolumn{3}{c}{$\begin{array}{c}\text { Stimulation (normal } \mathrm{K}^{+} / \mathrm{low}^{+} \text {) of } \\
\text { incorporation into }\end{array}$} \\
$\begin{array}{ccc}\text { Slice } \\
\text { protein }\end{array}$ & $\begin{array}{c}\text { Intracellular } \\
\text { albumin (I) }\end{array}$ & $\begin{array}{c}\text { Extracellular } \\
\text { albumin (E) }\end{array}$ \\
$0.9 \pm 0.1$ & $1.1 \pm 0.3$ & $1.6 \pm 0.1$ \\
$1.3 \pm 0.3$ & $1.5 \pm 0.2$ & $1.7 \pm 0.2$
\end{tabular}

radioactivity attributed by him to intracellular albumin is actually present as such. The consequence is that a marked time-lag is now recognized in the appearance of label in the intracellular albumin, contrasted with the labelling of total liver protein (not shown), which is labelled without discernible delay.

The specific radioactivity of the microsomal albumin far exceeds that of the total albumin or the albumin in the cytosol and (by difference) that in other fractions not isolated. Further, the microsomal fraction contained about $30 \%$ of the total liver albumin, but contained between $70-80 \%$ of the ${ }^{14} \mathrm{C}$-labelled albumin. This suggests the microsomal albumin as the possible source of the extracellular fraction. However, we calculated the specific radioactivity of the newly secreted extracellular albumin in this experiment, assuming a secretory rate of $1.2 \mathrm{mg}$ of serum albumin $/ \mathrm{h}$ per $\mathrm{g}$ of liver (Gordon \& Humphrey, 1961 ; Peters, 1962) and assuming an extracellular pool of $500 \mathrm{mg}$ of serum albumin in our rats (body wt. $200 \mathrm{~g}$ ). The results are illustrated in Fig. 3(b), which also shows the specific radioactivity of microsomal albumin for comparison. No precursor relationship is apparent.
In Fig. 3, each time-point represents results obtained with only one rat. However, the relationships between the intracellular and extracellular fractions of labelled albumin remain constant in each of the eight animals and are sufficient to make our point.

Extracellular albumin pool. We measured the amount of serum albumin appearing in the Ringer solution, using exactly the same conditions as for the labelling experiments. After the initial preincubation of $60 \mathrm{~min}$ the slices were transferred to fresh Ringer solution. In a typical experiment, with 40 slices in batches of five and taking eight time-intervals, the albumin in the Ringer solution increased from $0.5 \mathrm{mg} / \mathrm{g}$ of slice (dry wt.) to about $1.3 \mathrm{mg} / \mathrm{g}$ of slice (dry wt.) in $120 \mathrm{~min}$. The relatively high zero-time value means that any measurements of specific radioactivity of the extracellular albumin will err on the low side.

\section{DISCUSSION}

The work of Schreiber et al. (1969) and of Rotermund, Schreiber, Maeno, Weinssen \& Weigand (1970) demonstrated the radiochemical impurity of 
Table 3. Specific radioactivities and serum albumin contents of slices at low and normal $\mathrm{K}^{+}$

All details were as Table 1. Cycloheximide $(100 \mu \mathrm{M})$ was used to stop labelling. Time of incubation was $120 \mathrm{~min}$. The albumin content was determined by isotope dilution as described in the Materials and Methods section.

$\begin{array}{cc}\begin{array}{c}\mathrm{K}^{+} \text {content of liver } \\ (\mu \mathrm{mol} / \mathrm{g} \text { dry wt. }) \text { at } \\ \text { end of }\end{array} \\ \overbrace{\text { Labelling }}^{\text {Incubation } 2} \\ 152 & 142 \\ 152 & 305 \\ 305 & 315\end{array}$

\begin{tabular}{|c|c|c|c|}
\hline \multicolumn{4}{|c|}{ Albumin } \\
\hline \multicolumn{2}{|c|}{$\begin{array}{c}\text { Content } \\
\text { (mg/g dry wt.) }\end{array}$} & \multicolumn{2}{|c|}{$\begin{array}{c}\text { Specific radioactivity } \\
\text { (d.p.m./mg of protein) }\end{array}$} \\
\hline Intracellular & Extracellular & Intracellular & Extracellular \\
\hline 1.25 & 1.60 & 1900 & 5370 \\
\hline 1.17 & 1.20 & 3150 & 9700 \\
\hline 1.54 & 2.00 & 4100 & 15350 \\
\hline
\end{tabular}
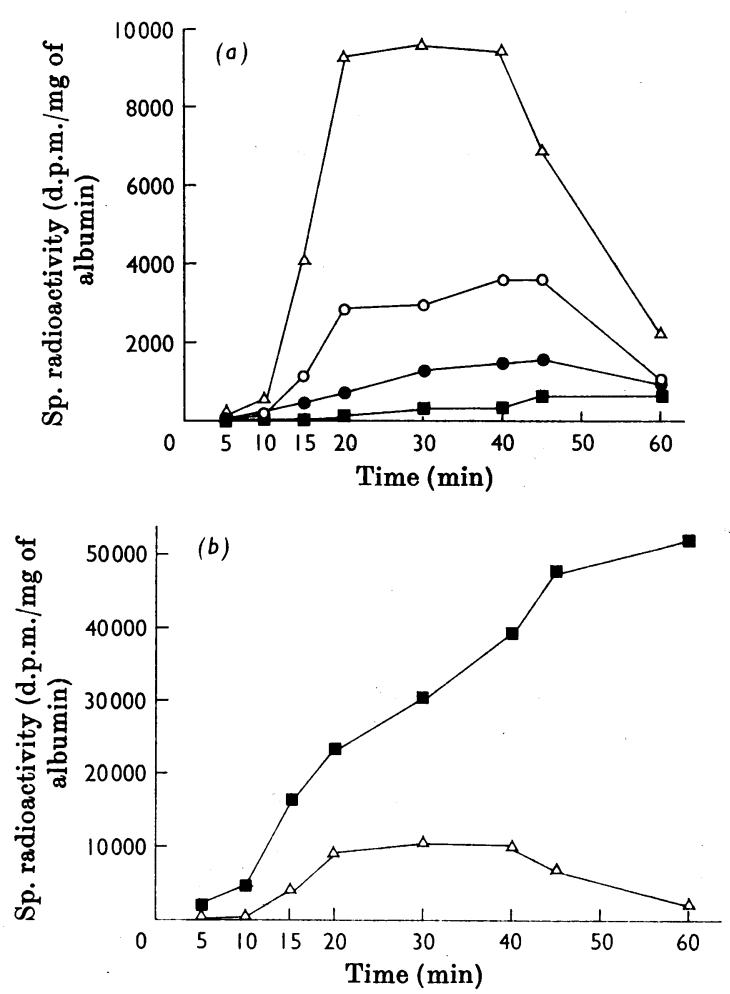

Fig. 3. (a) Distribution and specific radioactivity of albumin in rat liver and $(b)$ comparison for extracellular and microsomal albumin. Female rats (about $200 \mathrm{~g}$ body wt.) were given intraperitoneal injections of $\mathrm{L}-\left[1-^{14} \mathrm{C}\right]$ leucine $(2.5 \mu \mathrm{Ci} / 100 \mathrm{~g}$ body wt. $)$ and were killed at the times shown. Samples of liver and blood were collected as described in the Materials and Methods section. Each time point shows the results from a single rat. E, Extracellular albumin; $\Delta$, microsomal albumin; $O$, total liver albumin; •, cytosol albumin.

serum albumin separated by simple antibody precipitation from whole liver. This led to the assumption that much of the earlier work on the incorporation of amino acids into intracellular serum albumin might well be erroneous (see Campbell \& Lawford, 1968, for references). The present work, arising out of our previous paper (Judah \& Nicholls, 1970), shows that there is a considerable time-lag in the appearance of label in intracellular albumin and that the addition of cycloheximide, after the start of labelling but during the time-lag, does not prevent the appearance of label in the intracellular or extracellular albumin. The extent of labelling increases with time and the sum of the radioactivity of intracellular and extracellular label also increases with time for 60-90 min after the start of labelling.

Consecutive labelling experiments with ${ }^{\mathbf{3}} \mathrm{H}$. labelled and ${ }^{14} \mathrm{C}$-labelled amino acids confirm that the cycloheximide is perfectly effective at the concentration used $(100 \mu \mathrm{M})$ and the results are identical when labelling is stopped with carrier amino acid or with a combination of this and cycloheximide. We conclude that a peptide precursor of serum albumin is formed and slowly converted into the complete protein. Evidence is presented that this conversion is accelerated by $\mathrm{K}^{+}$.

These findings explain the results of our previous paper (Judah \& Nicholls, 1970), where we observed that the rate and extent of the secretion of extracellular albumin by liver slices was dependent on the concentration of $\mathrm{K}^{+}$in the liver cells. Our earlier findings based on simple antibody precipitation of extracellular albumin are amply confirmed by the more refined methods used in this work.

The finding that $\mathrm{K}^{+}$does not alter the transit time of labelled serum albumin surprised us, but there are possibilities in which the conversion of precursor and the rate of transit through channels in the endoplasmic reticulum would be interdependent and an effect on either would be indistinguishable. This would happen if the peptide precursor were converted into the end product by a system fixed to the membranes of the endoplasmic reticulum so that the rate of conversion depended on the rate of movement. Alternatively, the con- 
version could be effected in some organelle to which the peptide had to move through the endoplasmic reticulum, and from which the complete protein were secreted.

This last possibility is made attractive by our findings that precursor relationships are not observed when the microsomal serum albumin is com. pared with the newly secreted extracellular albumin (see Fig. 3b). We suggest the possibility that serum albumin destined for the extracellular pool is not formed until just before secretion and that almost all the newly formed intracellular albumin will be found in some small fraction of the endoplasmic reticulum, presumably the Golgi apparatus, which should also be the site of conversion of precursor into albumin. If so, this albumin will have the same specific radioactivity as that found in the serum and it will have an exceedingly short turnover time, far less than the $22 \mathrm{~min}$ calculated by Gordon \& Humphrey (1961) for whole liver albumin, and less even than the 5 or 6 min which would be predicted if the whole microsomal component were the pre- cursor for the extracellular fraction. This suggestion is open to experimental approach.

We are indebted to the U.S. Public Health Service (Grant AM 11468), the British Empire Cancer Campaign and the Medical Research Council for financial assistance. We thank Dr B. D. Gomperts and Dr D. M. Geller for much advice.

\section{REFERENCES}

Campbell, P. N. \& Lawford, G. R. (1968). In Structure and Function of the Endoplasmic Reticulum in Animal Cells, p. 57. Ed. by Gran, F. C. London and New York: Academic Press.

Gordon, A. H. \& Humphrey, J. H. (1961). Biochem. J. 78, 551 .

Judah, J. D. \& Nicholls, M. R. (1970). Biochem. J. 116, 663.

Judah, J. D. \& Nicholls, M. R. (1971). Biochem.J.123, 643.

Peters, T., jun. (1962). J. biol. Chem. 237, 1186.

Rotermund, H. M., Schreiber, G., Maeno, H., Weinssen, U. \& Weigand, K. (1970). Cancer Res. 30, 2139.

Schreiber, G., Rotermund, H. M., Maeno, H., Weigand, K. \& Lesch, R. (1969). Eur.J. Biochem. 10, 355. 